\section{DIACRONIE}

\section{Diacronie}

Studi di Storia Contemporanea

$\mathrm{N}^{\circ} 13,1 \mid 2013$

Contrabbandieri, pirati e frontiere: per una storia delle pratiche informali nell'America Centrale (XVII-XXI

secolo)

\title{
Acercamiento conceptual a las prácticas económicas informales en los pasos fronterizos entre México y Guatemala
}

Jean Clot

\section{(2) OpenEdition \\ Journals}

\section{Edición electrónica}

URL: http://journals.openedition.org/diacronie/740

DOI: 10.4000/diacronie.740

ISSN: 2038-0925

Editor

Association culturelle Diacronie

\section{Referencia electrónica}

Jean Clot, «Acercamiento conceptual a las prácticas económicas informales en los pasos fronterizos entre México y Guatemala », Diacronie [En línea], № 13, 1 | 2013, documento 9, Puesto en línea el 01 abril 2013, consultado el 20 abril 2019. URL : http://journals.openedition.org/diacronie/740 ; DOI : 10.4000/diacronie.740 


\section{Diacronie}

\section{Acercamiento conceptual a las prácticas económicas informales en los pasos fronterizos entre México y Guatemala}

Jean CLOT *

En la época contemporánea, la economía informal constituye un fenómeno complejo y heterogéneo. Existe un abanico de actividades que se desempeñan al margen del la regulación y del control de los Estados. En este trabajo partiremos de la idea de que existe un cierto tipo de informalidad relacionada con el diferencial o la discontinuidad que provoca la frontera político-administrativa, abordado comúnmente en términos de "contrabando". El objetivo será proponer una conceptualización de este tipo de informalidad a partir de contribuciones teóricas sobre economía informal y frontera. La región fronteriza entre México y Guatemala nos servirá de marco contextual y nos procurará ilustraciones específicas.

\section{Introducción}

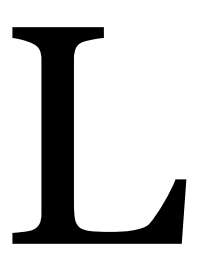

a intención de identificar una economía informal específicamente vinculada a la frontera nace como resultado de observaciones empíricas en los pasos fronterizos entre el departamento de San Marcos, Guatemala y el estado de Chiapas, México, áreas que concentran una diversidad de actividades económicas no controladas por los Estados ${ }^{1}$. Existen, por ejemplo, organizaciones de "pasadores" que se dedican a trasladar personas y mercancías al margen de los puntos

\footnotetext{
${ }^{1}$ Cabe mencionar que las reflexiones de este artículo se inscriben en el marco de un trabajo de investigación de doctorado enfocado a los modos de organización de los grupos sociales que se dedican al comercio informal transfronterizo.
} 
de internación oficiales, así como un comercio transfronterizo que escapa a los controles de los gobiernos. Son prácticas comúnmente abordadas en términos de "contrabando", sin embargo dicha noción no alcanza a poner de relieve la especificidad y la diversidad de las interacciones e intercambios informales entre ambos países. Si bien esclarece dichos fenómenos, lo hacen de manera parcial. Es necesario recurrir también a otros conceptos para aprehender esta realidad.

Buscamos en este trabajo examinar ciertos planteamientos teóricos referentes a la informalidad económica y vincularlos con el abordaje conceptual sobre frontera. Efectivamente, por una parte la frontera desempeña una serie de funciones (de control, por ejemplo) y provoca efectos que afectan los intercambios socioeconómicos - que sean formales o informales - pero por otra, es a menudo instrumentalizada por las poblaciones fronterizas que buscan oportunidades económicas a partir de la discontinuidad que instaura. Surgen entonces diversas actividades económicas en el margen de la regulación de los Estados, así como estrategias para esquivar los controles fronterizos.

Asimismo, propondremos un acercamiento conceptual a dichas prácticas económicas informales, preguntándonos si, entre el abanico de actividades que integran la economía informal, existen ciertos tipos específicamente relacionados con la frontera y la ruptura que implica. Enfatizaremos en el contexto específico de la frontera entre México y Guatemala en donde la tensión entre legalidad e ilegalidad es parte de la vida cotidiana, por emplear la expresión de Grimson².

\section{Breve panorama contextual}

De acuerdo con los datos proporcionados por instancias mexicanas, como el Instituto Nacional de Geografía y Estadística (INEGI), la frontera sur de México alcanza $1149 \mathrm{~km}$ de extensión total y divide el país de las Repúblicas de Guatemala (longitud de $956 \mathrm{~km}$ ) y Belice (193 km). Existen 8 puntos de paso internacionales entre México y Guatemala (7 en el estado de Chiapas y uno en Tabasco), reconocidos por ambos países; y 2 entre Belice y México en el Estado de Quintana Roo³. Por otra parte,

2 GRIMSON, Alejandro, «Pensar fronteras desde las fronteras», in Nueva Sociedad, 170, 6/2000, p. 3.

3 Vid. INSTITUTO NACIONAL DE ESTADÍSTICAS Y GEOGRAFÍA, Resultados de la encuesta nacional de ocupación y empleo periodo octubre-diciembre de 2012, Aguascalientes, INEGI, 2013. 
existen cientos de pasos peatonales, al margen de los puntos oficiales de internación, y más de 50 cruces vehiculares informales a lo largo de la frontera 4 .

La frontera fue delimitada tanto por elementos geodésicos, como por elementos naturales, como el río Suchiate que sirve de soporte al tramo occidental de frontera entre el departamento de San Marcos en Guatemala y la región Soconusco en el estado de Chiapas en México5. Cabe señalar que es en esta región que han ocurrido mayores interacciones fronterizas.

Desde una perspectiva histórica, De Vos señala que los límites políticoadministrativos entre México y Guatemala son el resultado de una serie de proyectos de expansión que los han configurando progresivamente, ello desde la época prehispánica y posteriormente en la época colonial con las ambiciones españolas e inglesas de dominio de la región ${ }^{6}$. Después de la independencia de México y Guatemala en la primera mitad del siglo XIX, los diferentes proyectos nacionales de expansión han configurado progresivamente la frontera hasta el reconocimiento bilateral de los límites comunes en 1882, proceso no exento de disputas y de reajustes en cuanto al trazado7.

Es importante señalar que los Estados nacionales, como lo menciona Grimson, no siempre pueden controlar las estructuras políticas que establecen en sus extremidades ${ }^{8}$; este fenómeno ha sido señalado en el caso de México: «la imprecisión de los linderos, lo agreste del terreno y la escasez de recursos determinaron que le gobierno de Chiapas no

4 INSTITUTO NACIONAL DE MIGRACIÓN, La experiencia de México en la documentación de trabajadores fronterizos guatemaltecos, Conferencia Regional sobre Migración, 28 de abril de 2011,

URL:

<www.crmsv.org\%2FEventos\%2FOtros\%2FAbril2011\%2FPresentaciones\%2FMEX\%2520-

\%2520Ernesto\%2520Rodr\%25EDguez\%2520-

\%2520Trabaj\%2520migrat\%2520en\%2520Mex.pptx\&ei=7AaKUIHrBcm-

yQGt24HoAw\&usg=AFQjCNHhI1mpXkG6KYSucN5U9xLpN-ouVA>, [consultado el 27 enero 2013]

5 Ver anexo 1.

6 DE VOS, Jan, Las fronteras de la frontera sur: reseña de los proyectos de expansión que figuraron la frontera entre México y Centroamérica, Villahermosa, Universidad Juárez Autónoma de Tabasco - Centro de Investigaciones y Estudios Superiores en Antropología Social, 1993.

7 Cabe mencionar que el actual estado mexicano de Chiapas se encontró literalmente en el medio de estos ajustes y reacomodos geográficos y políticos. La entidad integraba la Capitanía General de Guatemala que formaba parte del Virreinato de Nueva España. Después de la proclamación de la independencia de la Provincia de Guatemala en 1821 y la constitución de las Provincias Unidas del Centro de América (que comprendían el actual Estado de Chiapas, Guatemala, El Salvador, Honduras, Nicaragua y Costa Rica), la Provincia de Ciudad Real de Chiapas fue anexada formalmente a México en el 1824, después de una consulta popular (DE VOS, Jan, op. cit.). Con el derrumbo de las Provincias Unidas, Guatemala se vuelve un país independiente en 1839. Posteriormente, el gobierno guatemalteco siguió reivindicando y reclamando las tierras chiapanecas, hasta la firma del Tratado de Límites en 1882 (que entró en vigor en 1892), en el cuál renuncia a sus derechos sobre Chiapas.

8 Vid. GRIMSON, Alejandro, «Pensar fronteras desde las fronteras», cit., pp. 1-5. 
pudiera ejercer un control efectivo sobre las regiones fronterizas que, convertidas en "tierra de nadie", eran refugio habitual de forajidos y facciosos»9.

Por otra parte, si bien existe una discontinuidad política entre ambos países, varios autores enfatizan en la continuidad sociocultural de la región y la historia común frente al colonialismo. Efectivamente, las poblaciones del norte de Guatemala y del sur de México, en particular del estado de Chiapas, comparten un pasado prehispánico común; existen fuertes lazos históricos y culturales de pueblos cuyos orígenes son anteriores a la conformación de los Estados modernos ${ }^{10}$.

Ello ha propiciado un espacio de intensa movilidad transfronteriza. Además de los migrantes en tránsito, de los jornaleros guatemaltecos (que trabajan temporalmente en Chiapas, principalmente durante la cosecha del café) o de los turistas, existe una población móvil de residentes fronterizos que se desplaza en forma recurrente entre ambos países. Existe un gran dinamismo en cuanto a los flujos y modalidades de movilidad $^{11}$. Este dinamismo llevó a ciertos autores a hablar de "espacio transfronterizo"; argumentan, por una parte, que la migración y la movilidad poblacional configuran un mecanismo de integración regional, y por otra que surgen "comunidades transnacionales", es decir redes de relaciones sociales, culturales y económicas que superan la división político-administrativa ${ }^{12}$.

Las poblaciones que viven de un lado y del otro de la frontera no comparten sólo dimensiones sociales y culturales a raíz de procesos históricos y políticos, sino también un cierto perfil socioeconómico. Los municipios del sur de México y del norte de Guatemala presentan similitudes en cuanto a la situación socioeconómica, sobre todo si los comparamos con los respectivos promedios nacionales; son regiones periféricas, en los confines de los Estados, que presentan un rezago económico; «este es el signo que

9 CASTILlO, Manuel Angel, TOUSSAINT RIBOT, Mónica, VÁZQUEZ OLIVERA Mario, Espacios diversos, historia en común. México, Guatemala y Belice: la construcción de una frontera, México D.F., Secretaría de Relaciones Exteriores, Dirección General del Acervo Histórico Diplomático, 2006, p. 81.

10 Vid. FÁBREGAS PUIG, Andrés, ROMÁN GARCÍA Carlos, Al fin del milenio: el rostro de la frontera sur. Tuxtla Gutiérrez, Instituto Chiapaneco de Cultura, 1994; CANALES, Alejandro I., MARTÍNEZ PIZARRO, Jorge, REBOIRAS FINARDI, Leandro, RIVERA POLO, Felipe, Migración y salud en zonas fronterizas: informe comparativo sobre cinco fronteras seleccionadas, Santiago de Chile, Naciones Unidas, 2010.

${ }^{11}$ Vid. CASTILLO, Manuel Ángel, Región y frontera: la frontera sur de México, Tapachula, El Colegio de la Frontera Sur, 1997; CRUZ, Hugo, ROJAS WIESNER, Martha, «Migración femenina internacional en la frontera sur de México» in Papeles de Población, VI, 23, 1/2000, pp. 127-151; MARTÍNEZ VELASCO, Germán, Presencia centroamericana en la frontera sur de México: un espacio en construcción transnacional, in PILCH ORTEGA, Angela, SCHRÖTTNER, Barbara, Transnational Spaces and Regional Localization, Münster, Waxmann, 2012.

12 CANALES, Alejandro I., MARTíNEZ PIZARRO, Jorge, REBOIRAS FINARDI, Leandro, RIVERA POLO, Felipe, Migración y salud en zonas fronterizas: informe comparativo sobre cinco fronteras seleccionadas, Santiago de Chile, Naciones Unidas, 2010, p. 37. 
caracteriza a esta región, la mayor pobreza, precariedad y vulnerabilidad social de su población. Si los datos indican una convergencia entre ambos lados de la frontera, ello no se debe a un proceso de desarrollo social y económico, sino más bien a su ausencia» ${ }^{13}$.

En este contexto, y particularmente a nivel local en los pasos fronterizos ${ }^{14}$, los actores individuales y colectivos tratan de aprovechar la frontera y se conforman sistemas paralelos de intercambios. Respecto a la definición y delimitación espacial de dichos pasos fronterizos, recurriremos a la noción de "área de frontera" propuesta por Oliveros: se trata de una franja de territorio cuya extensión geográfica no rebasa unos cuantos kilómetros cuadrados y que está íntimamente asociada a la noción de linealidad de la frontera y al trazado fronterizo: «en ella, la manifestación tangible del fenómeno fronterizo ocurre a una escala local y se patentiza con el funcionamiento de los pasos de frontera -algunos de ellos habilitados por acuerdo de los Estados y otros informales - y la existencia de infraestructura y servicios vinculados a su utilización» ${ }^{15}$. $\mathrm{El}$ autor señala también la presencia de agentes y actividades específicas en esta área: guarniciones militares o puestos de control, así como servicios relacionados con el cambio de moneda o las telecomunicaciones.

\section{Frontera y transgresión}

Varios planteamientos teóricos sobre la economía informal pueden contribuir a enriquecer los estudios sobre frontera y viceversa. Recordamos que desde los primeros análisis de Ratzel a finales del siglo XIX, los estudios de frontera se volvieron progresivamente durante el siglo XX un objeto de pleno derecho en geografía. A partir de los años ochenta, la frontera se ha vuelto objeto de interés de numerosos investigadores, no solamente en geografía, sino también en ciencias políticas, en historia, en economía o en sociología. Kolossov habla de "tendencia posmoderna" para referirse a estos análisis que buscan superar ciertos enfoques tradicionales en donde la

\footnotetext{
13 Ibidem, p. 31.

14 Ver anexo 2

15 OLIVEROS, Luis Alberto, El concepto de frontera en el contexto y en la perspectiva de la integración andina, Comunidad Andina, Febrero de 2002, URL: <http://www.comunidadandina.org/documentos/docIA/IA13-2-02.htm> [consultado el 27 de enero 2013].
} 
frontera aparece esencialmente como la manifestación territorial de fuerzas políticas antagónicas ${ }^{16}$.

No obstante, son relativamente pocos los estudios que se centraron en un fenómeno inherente a la frontera: la transgresión. Como lo sugiere Raffestin, el límite en sí - que incluye la frontera como categoría - está íntimamente relacionado con la noción de transgresión ${ }^{17}$. De acuerdo con él, encontramos el límite en todos los grandes mitos, como la fundación de Roma; Rómulo establece los límites de la futura ciudad ejerciendo «la función social del ritual y de la significación social de la línea, del límite, cuyo ritual licita el paso, la transgresión» ${ }^{18}$. El límite instaura un orden como lo indica el autor, pero es rápidamente transgredido. Rómulo mata a su hermano cuando este se atreve a traspasar el surco sagrado.

Del latín transgredior - transgredi que significa "ir más allá" o "cruzar", la transgresión implica atravesar lo que está institucionalizado: lo plasmado por escrito, formal u oficial, como la norma o la ley, pero también las instituciones informales, como los valores morales y éticos, las convenciones, tradiciones y costumbres. Mediante ella se cuestionan, se redefinen o se renegocian las reglas. Desde esta perspectiva, está intrínsecamente ligada a la noción de cambio. En el caso de la frontera la transgresión adquiere también una dimensión territorial: no se transgrede sólo el conjunto de reglamentos concerniendo el tránsito transfronterizo, sino también la mera línea divisoria. En todos casos, supone riesgos y oportunidades.

De ahí, dos observaciones preliminares: por una parte, la transgresión, como dimensión estructural de la frontera, toma diferentes formas según la evolución histórica de las instituciones ${ }^{19}$, por lo mismo tiene un carácter eminentemente cambiante y dinámico, al igual que las instituciones. Por ejemplo, sus facetas varían según los tipos de control que el Estado implementa en sus fronteras, así como la eficiencia en la aplicación de normas por dicho Estado; la demarcación territorial desempeña también un papel. Por otra parte, los elementos morfológicos (como los ríos, montañas o desiertos) que sirven a veces de soporte a la frontera políticoadministrativa condicionan los flujos de personas y mercancías que la atraviesan, que

${ }^{16}$ KOLOSSOV, Vladimir, «Border studies: changing perspectives and theoretical approaches» in Geopolitics, 10, 4/2005, pp. 606-632, p. 613.

${ }_{17}$ RAFFESTIN, Claude, «Éléments pour une théorie de la frontière», Diogène, 134, 2/1986, pp. 3-21.

${ }^{18}$ BOURDIEU, Pierre, citado por RAFFESTIN, Claude, cit., p. 3.

19 "Institucionalidad" como conjunto de instituciones en el sentido que les dio North (1990) como las reglas que estructuran las interacciones sociales, económicas o políticas y orientan a los agentes, determinando restricciones e incentivos. Existen instituciones formales, como las leyes y normas plasmadas por escrito, e instituciones informales, como los códigos de conducta, las tradiciones, las costumbres o las normas tácitas. 
sea al margen del control de los gobiernos o por los pasos oficiales. Al igual que las terrestres, las fronteras marítimas generan también dinámicas específicas en cuanto a los intercambios. Sin embargo, la construcción de muros, así como el fenómeno de securitización de la frontera, como es el caso entre México y Estados Unidos, afecta las prácticas económicas informales o ilegales: implican determinadas estrategias de evitamiento para evadir los controles fronterizos.

Es importante señalar finalmente que las diferencias existentes de un país a otro, en términos económicos y a nivel político (marcos jurídicos, institucionales y administrativos diferentes) estimulan dichas prácticas. Dicho de otro modo, fuertes discontinuidades $\mathrm{y}$ desequilibrios ofrecen potencialidades a las transgresiones fronterizas.

\section{Economía informal de frontera}

La transgresión de la frontera político-administrativa ha sido comúnmente abordada en términos de "contrabando" o recurriendo a conceptos como la "informalidad" que caracteriza los cruces fronterizos y ciertas prácticas económicas. Veamos los alcances y limitaciones de dichos conceptos, aplicados a la frontera.

El término "contrabando", del italiano contrabbando, «en contra del bando público, en contra de la ley» ${ }^{20}$, es del siglo XVI y califica la importación clandestina de mercancías que pueden ser prohibidas o por las cuales se deben de pagar derechos arancelarios. Aparece también en el siglo XVII el equivalente inglés: smuggle, es decir, el hecho de sacar o introducir a un país mercancías de manera ilegal. La noción es entonces eminentemente legalista

Aplicada a un escenario de frontera, la noción se refiere esencialmente a una determinada práctica, es decir traspasar la frontera con mercancías que pueden ser prohibidas, pero también falsificadas, robadas, fraudulentas o que incumplan con los requisitos establecidos por la autoridad. Aunque puede ser útil para caracterizar una acción, no pone de relieve la intención subyacente y la finalidad de dicha acción y tampoco nos brinda información acerca de los significados subjetivos que fundamentan esa práctica. Como menciona Grimson en el caso de las fronteras, «las transacciones comerciales entre las poblaciones [fronterizas] son consideradas muchas veces como “contrabando" por los Estados mientras es la actividad más natural para la gente del

\footnotetext{
${ }^{20}$ Diccionario de la Academia Francesa.
} 
lugar» ${ }^{21}$. Es decir, la normalidad vista desde el centro difiere de la normalidad vista desde la periferia, desde los confines de los Estados, como lo señaló Grimson respecto a las fronteras argentinas y como se puede constatar en el espacio limítrofe entre México y Guatemala.

Por otra parte, el contrabando designa tanto productos ilegales, por ejemplo ciertos estupefacientes, como productos legales cuyos impuestos no fueron pagados. Estas mismas dimensiones, es decir, la apertura de la noción y las diferencias de significados que puede tener, la impregnan de subjetividad, y por lo mismo puede ser sujeto de múltiples interpretaciones.

Además, si nos enfocamos en el contexto de la frontera entre México y Guatemala, se puede encasillar desde esta perspectiva legalista, tanto a los indígenas de origen maya que habitan el espacio transfronterizo entre México y Guatemala y que vienen a abastecerse en los pasos fronterizos, como a las personas que se dedican al llamado tráfico, contrabando o comercio "hormiga" $22 \mathrm{o}$ al comercio de productos de escaso valor económico; se trata esencialmente de actividades de subsistencia. No obstante existen grupos más organizados y jerarquizados que se dedican principalmente al contrabando de alcohol, gasolina y cigarros, manejando volúmenes mucho más importantes si los comparamos con los precedentes. Ello sin mencionar los tráficos de personas, de drogas, de armas, y de especies protegidas de fauna y flora, entre otros; recordamos que el sur de México y el istmo centroamericano constituyen uno de los tres corredores, el terrestre, para la droga que tiene como destino final los Estados Unidos ${ }^{23}$.

Frente a esa heterogeneidad de los actores individuales o colectivos, de las prácticas y de las lógicas subyacentes, el concepto de "contrabando" puede no es suficiente para explicar la heterogeneidad del fenómeno. Por lo mismo, es necesario establecer una primera distinción entre las actividades que conciernen productos ilegales y actividades que se encuentran "a medio camino" entre legalidad e ilegalidad, relacionadas con mercancías legales, tal como lo propusieron teóricos que se centraron en estos fenómenos. Portes y Haller, por ejemplo, señalan que, aunque comparten algunas dimensiones (los productos no se registran o declaran), la economía ilegal y la economía informal tienen también características propias; por ello debemos

\footnotetext{
${ }^{21}$ GRIMSON, Alejandro, «Pensar fronteras desde las fronteras», cit., p. 3.

$22 \mathrm{El}$ hecho de cruzar la frontera repetidas veces introduciendo productos en pequeñas cantidades como si fueran para el uso personal.

${ }^{23}$ Vid. VILLAFUERTE SOLÍS, Daniel, La frontera sur de México. Del TLC MéxicoCentroamérica al Plan Puebla-Panamá, México D.F., UNAM, Plaza y Valdés, Daniel Villafuerte Solís, 2004.
} 
diferenciarlas conceptualmente. «Los sociólogos reconocen que lo legal y lo delictivo, lo mismo que lo normal o lo anormal, son categorías definidas socialmente, y que pueden cambiar. No obstante, las actividades ilícitas suponen la producción y comercialización de bienes, definidos en un lugar y un momento determinados como ilegales, mientras que en la mayoría de los casos, las actividades informales están relacionadas con bienes lícitos» 24 .

La informalidad en su primer sentido, significa «el hecho de no guardar las formas y reglas prevenidas» ${ }^{25}$ y surgió en el siglo XX. Si bien se ha aplicado comúnmente el término a maneras de vestirse y comportarse o para calificar el lenguaje en un contexto marcado justamente por determinadas reglas y convenciones, hace relativamente poco que su uso se extendió a la esfera del trabajo y de las actividades económicas. Como lo señala Adler-Lomnitz sustituyó la palabra “marginalidad” mediante la cual se refería en los sesenta a los grupos sociales excluidos del proceso de control económico, político y social, en contextos urbanos en América Latina. Al investigar ese tipo de exclusión, «se vio que lo que caracterizaba al sector, más que el nivel de ingresos o el tipo de ocupación, era la naturaleza informal, no contractual, lo que tenía como principal consecuencia una inseguridad en sus ocupaciones, en sus ingresos y la falta de una protección laboral legal» ${ }^{26}$. En este contexto, la autora subraya que las redes sociales (familiares, amistades, vecinos, conocidos, etc.) actuaban como un sistema de seguridad social informal.

Es el antropólogo Hart quien a principios de los años setenta acudió al concepto de "informalidad" al analizar el mercado laboral durante investigaciones en Ghana y Kenia $^{27}$; se trataba sobre todo de diferenciar el sector laboral remunerado de otro amplio sector de la población que trabaja por cuenta propia, en actividades muy diversas. Desde entonces el concepto se ha enriquecido considerablemente gracias a las aportaciones de sociólogos, antropólogos y economistas, a medida de que se iba

\footnotetext{
${ }^{24}$ PORTES, Alejandro, HALLER William, «La economía informal» in CEPAL, Series Políticas Sociales, 100/2004, p. 11.

${ }^{25} \mathrm{Si}$ bien encontramos la idea de «no guardar las formas prevenidas», tal como lo indica el Diccionario de la Real Academia Española, en la mayoría de los diccionarios, cabe mencionar que en el Diccionario de la Academia Francesa, se hace énfasis en el rechazo de las reglas tradicionales en el campo artístico, cuando en el Diccionario de Oxford, se refiera primero a estilos, naturalezas o maneras extraoficiales, e incluso amistosas o relajadas. Desde esta perspectiva, un ambiente, una reunión o relaciones sociales pueden ser informales.

${ }^{26}$ ADLER-LOMNITZ, Larissa, Redes sociales, cultura y poder: ensayos de antropología latinoamericana, México D.F. , FLACSO-Miguel Ángel Porrúa, 1994, p. 134.

${ }^{27}$ Vid. HART, Keith, «The idea of the Economy: Six Modern Dissenters» in FRIEDLAND, Roger, ROBERTSON, A.F., Beyond the Marketplace, Rethinking Economy and Society, New York, Aldine de Gruyter, 1990.
} 
descubriendo la magnitud del fenómeno. Efectivamente existe una gran variedad de actividades económicas consideradas como "informales". Diferenciando implícitamente lo informal de lo ilegal, Castells y Portes indican que se trata de «todas las actividades generadoras de ingresos no reguladas por el Estado en entornos sociales en que sí están reguladas actividades similares» ${ }^{28}$.

El fenómeno está presente en países de altos ingresos; citemos actividades tales como los servicios domésticos, la jardinería, o los servicios en hoteles y restaurantes, así como los trabajos no calificados o semi-calificados, realizados a menudo por inmigrantes indocumentados, en varios sectores, como la agricultura, la construcción de edificios, la industria textil o de empacado de carne, entre otros ejemplos ${ }^{29}$.

En América Latina, el fenómeno es visible en la cotidianeidad. Se trata de un contexto de economía informal "generalizada y semiabierta"3o. Se señala que en esta región del mundo la economía informal se expandió entre 1990 y 2005 de 57 al 63.3 por ciento del empleo no agrícola. Sin embargo, hay importantes diferencias regionales: el sector informal en ciertos países como Guatemala supera el 70 por ciento del empleo, cuando en otros países como México se asemeja al promedio latinoamericano, o cuando en Chile y Costa Rica representa menos del 40 por ciento de la economía ${ }^{31}$. Podemos observar esta heterogeneidad en un mismo país: las estimaciones del INEGI en cuanto a informalidad laboral en el estado de Chiapas se acercan más a las cifras de Guatemala que al promedio mexicano ${ }^{2}$.

Los puestos improvisados en las calles de las grandes ciudades en donde se vende comida es una de las manifestaciones más evidente de la informalidad económica, sin embargo, una parte importante de la población económicamente activa integra este sector económico informal. En su mayoría, son trabajadores por cuenta propia no

${ }^{28}$ CASTELLS, Manuel, PORTES, Alejandro, World Underneath: The Origins, Dynamics, and Effects of the Informal Economy, in PORTES, Alejandro, CASTELLS, Manuel, BENTON Lauren, The Informal Economy: Studies in Advanced and Less Developed Countries, Baltimore, The Johns Hopkins University Press, 1989, p. 12.

${ }^{29}$ Vid. CASTLES, Stephen, MILLER, Mark J., La era de la migración. Movimientos internacionales de población en el mundo entero, México D.F., Universidad Autónoma de Zacatecas, Secretaría de Gobernación, Fundación Colosio, Miguel Ángel Porrúa, 2004; PORTES, Alejandro, HALLER, William, «La economía informal», in CEPAL, Series Políticas Sociales, 100, 2004, pp. 1-55.

${ }^{30}$ PORTES, Alejandro, HALLER, William, «La economía informal», cit., p. 37.

${ }^{31}$ Vid. TOKMAN, Victor E., «Flexiguridad con informalidad: opciones y restricciones», in CEPAL - Serie Macroeconomía del desarrollo, 70, 2008, pp. 1-57.

${ }^{32}$ Vid. INSTITUTO NACIONAL DE ESTADÍSTICAS Y GEOGRAFÍA, Resultados de la encuesta nacional de ocupación y empleo periodo octubre-diciembre de 2012, Aguascalientes, INEGI, 2013. 
calificados, pero también trabajadores en microempresas, y en servicios domésticos, que carecen de derechos y protección social. Es importante mencionar que el límite entre la economía informal y la economía formal no es rígido; se estima que el 20 por ciento de los trabajadores informales en Latinoamérica trabajan en empresas formales 33 .

Por otra parte, cabe señalar que la informalidad no concierne exclusivamente el comercio sino otras dimensiones de la sociedad, reguladas por el estado, como la vivienda y la propiedad privada o el transporte masivo de pasajeros, como lo ha indicado De Soto en el caso de Lima, Perú. Es decir, existen apropiaciones de terrenos, construcción informal de vivienda, creación de nuevas rutas de transporte o invasión de las rutas existentes por parte de transportistas informales, todo ello en margen del control del Estado34.

Enfatizando en los pasos fronterizos entre México y Guatemala, existe toda una variedad de actividades económicas informales propias de un lugar de paso, tal como lo podríamos observar en determinadas zonas de centros urbanos en ambos países. Efectivamente, alrededor de los puntos de tránsito, por ejemplo en las cercanías de las terminales de autobuses o en ciertas calles y parques, surgen - además de la venta ambulante - pequeños mercados o "tianguis" 35 que se caracterizan justamente por ser no establecidos formalmente; son puestos semi fijos donde podemos encontrar comida, artículos de ropa, de juguetería, artículos electrodomésticos, entre otros. Por ser lugares muy transitados, hay también servicios de alojamiento, restauración, comunicación y transporte que pueden ser en parte o totalmente informales.

Sin embargo, existe también una informalidad directamente vinculada con la frontera político-administrativa y la discontinuidad que genera, a nivel económico y a nivel político, con aparatos administrativos, marco jurídicos e institucionales distintos. En estas áreas de frontera - alrededor de los pasos fronterizos oficiales - se condensa entonces un cierto tipo de comercio transfronterizo que se genera a raíz: 1) del diferencial del tipo de cambio; 2) de los precios diferenciados de ciertos productos y 3 ) de la especialización productiva (la producción de fruta y verdura en Guatemala por ejemplo). Como lo vimos, existen varias modalidades: actividades económicas de

\footnotetext{
33 Vid. TOKMAN, Victor, E., op. cit.

34 Vid. DE SOTO, Hernando, El otro sendero, Lima, Editorial El Barranco, 1986.

$35 \mathrm{El}$ término proviene del náhuatl y significa "mercado" en México; los tianguis se caracterizan por ser semifijos y abiertos y ubicarse en espacios públicos.
} 
"subsistencia" o "sobrevivencia" de pequeña escala y un comercio manejado por grupos más estructurados ${ }^{36}$.

Además, se proporcionan varios servicios informales para facilitar el cruce del río, las cuales son actividades eminentemente complementarias. Es el caso del tramo de frontera en donde el río Suchiate divide los dos países: existen varias organizaciones tanto del lado mexicano como guatemalteco - cuyas actividades se relacionan con el transporte y traslado de mercancías y personas en margen de los puentes internacionales. Proponen una serie de servicios vinculados con el tránsito fronterizo. Sus actividades se caracterizan por su intercomplementariedad, tal como lo señaló Ordóñez, cuya investigación constituye el principal antecedente de estudio sobre economía informal en esta región específica ${ }^{37}$. El sistema de intercambios informales se compone de la manera siguiente: que sea de un lado o del otro de la frontera, los comerciantes informales contratan el servicio de "tricicleros" para llevar mercancías de los almacenes o locales (ubicados en las pequeñas ciudades fronterizas) hacia la orilla del río, posteriormente, los "cargadores" trasladan la mercancía a las balsas, y finalmente los "camareros" 38 la llevan al país vecino; sucede el mismo proceso del otro lado, la mercancía es descargada, etcétera. En general, el camarero no vuelve a atravesar la frontera con su balsa vacía, lleva otra vez a personas o mercancías. Existe todo un conjunto de reglas informales que rigen estos intercambios, una normatividad extralegal. A estas organizaciones informales que se encargan del transbordaje, se suman las organizaciones de "cambistas" quienes se encargan del cambio de divisas y de "tramitadores" que proponen agilizar los trámites aduaneros mediante remuneración.

Estas actividades conforman un sistema paralelo, informal, de traslado y transporte de dimensión transfronteriza. Es importante mencionar que estos actores colectivos son, como diría Zartman, agentes que no existirían si no fuera por la frontera ${ }^{39}$. En

\footnotetext{
${ }^{36}$ Este comercio transfronterizo concierne una variedad de productos. Combustibles, alcohol, tabaco, ganado, pollos, piezas y accesorios para automóviles, fertilizantes, productos de consumo corriente tales como frutas y verduras, maíz, frijol o azúcar constituyen una lista no exhaustiva, sino con valor descriptivo e ilustrativo.

${ }^{37}$ Vid. ORDÓÑEZ MORALES, César Eduardo, «Economía informal y sistema fronterizo en dos espacios locales situados en la frontera de Guatemala con México» in Revista de Geografía Agrícola, 38, 2007, pp. 85-100.

${ }^{38}$ El término proviene de la palabra "cámara de aire"; designa a las personas que pasan personas y mercancía sobre el río Suchiate, por medio de balsas hechas con neumáticos. Ver anexo 3.

${ }^{39}$ ZARTMAN, William, citado por ARMIJO CANTO, Natalia, Frontera sur de México: las retos múltiples de la diversidad in COLECTIVO DE ANÁLISIS DE LA SEGURIDAD Y DEMOCRACIA, Migración y seguridad: nuevos desafíos en México, México D.F., CASEDE, 2011, p. 49.
} 
efecto, esta constituye un recurso para un sector de la población. Señalemos también que la visibilidad de estos fenómenos en los pasos fronterizos sugiere, no sólo una tolerancia por parte de la autoridad, sino también ciertos nexos entre los funcionarios de gobierno y estos grupos informales, así como prácticas de corrupción.

La intensidad y direccionalidad de estos flujos de mercancías es variable, cambiante y depende en gran medida de procesos económicos y políticos coyunturales, por ejemplo las diferentes políticas fiscales que implementan los Estados que pueden generar diferencias de precios significativas de un lado y del otro de la frontera, diferencias que propician determinados circuitos de comercio informal transfronterizo. El contrabando de gasolina nos procura un ejemplo, cuando esta está subvencionada por el gobierno mexicano, es regida por el mercado en Guatemala, lo que ocasiona diferencias significativas de precio, y propicia un intenso comercio paralelo de México a Guatemala. Por otra parte, las diferencias en cuanto al marco institucional de un país y del otro modulan también estos flujos en el sentido de que les dan a los agentes determinadas márgenes de acción. Como lo plantea Raffestin, la frontera ejerce efectos, en el sentido de que yuxtapone dos tipos diferentes de soberanía política, dos estructuras organizacionales con políticas específicas (agrícolas, económicas, demográficas, ambientales, etc.). En este contexto, los grupos fronterizos buscan «aprovechar los contrastes o las oposiciones, o dicho de otro modo a valorizar ciertas discordancias generadas por políticas diferenciales» $4^{40}$.

Si bien están al margen del control de los gobiernos, no significa por lo tanto que estas actividades estén desvinculadas o desconectadas de la normatividad que prevalece, al contrario están estructuralmente relacionadas con las instituciones formales que se establecen, o con el tipo de gestión fronteriza (border management) instaurado. Sin embargo sería ingenuo pensar que a más control, a más reglamentos y parámetros de administración de la frontera corresponde un menor nivel de transgresión, o al revés, que la falta de regulación tenga como consecuencia el incremento del contrabando. Varios teóricos pusieron de relieve esta paradoja del control del Estado en las actividades económicas. Efectivamente el Estado interviene en la vida económica creando un "espacio formal" de transacciones, sin embargo esta "formalización" genera informalidad ya que esta conlleva al incremento de reglas: «cuanto mayor la amplitud y el alcance de las medidas de regulación que intenta aplicar el Estado, tanto más variadas serán las posibilidades de evitarlas»41. La paradoja

\footnotetext{
${ }^{40}$ RAFFESTIN, Claude, «Eléments pour une problématique des régions frontalières» in Espace géographique, 1974, p. 13. La traducción del francés al español es nuestra.

${ }^{41}$ PORTES, Alejandro, HALLER, William, «La economía informal», cit., p. 22.
} 
reside en que el no regular, no arbitrar el juego mediante una serie de reglas, se vuelve una puerta abierta al fraude generalizado, como lo indican los autores.

Encontramos una idea similar en el trabajo de Adler-Lomnitz quien argumenta que existen vínculos de interdependencia entre la economía formal e informal. Señala que «cuanto más se formaliza, regula y planifica burocráticamente un sistema social que no satisface las necesidades de la sociedad, tanto más suelen crearse mecanismos informales en los intersticios del sistema formal que escapan a su control. Así, la informalidad no sería un residuo del tradicionalismo, sino un elemento intrínseco de la formalidad, ya que es una respuesta a las deficiencias de la formalización» ${ }^{2}$.

A nuestro modo de ver, podemos hacer ciertos paralelos entre la formalización de la economía y lo que llamaremos la formalización de la frontera. Desde un enfoque teórico, Raffestin plantea que el establecimiento de una frontera se realiza en tres principales etapas o secuencias: la definición, la delimitación y la demarcación. La primera etapa concierne la negociación en cuanto a la frontera que divide las entidades, la segunda la delimitación cartográfica, y respecto a la última, cuya duración puede ser larga, se trata de hacer coincidir el mapa con el territorio, es decir poner señales concretas en el territorio que indican el limite político-administrativo. Esta última secuencia implica recursos (humanos, económicos, y materiales) y representa un problema arduo para los Estados, por lo mismo muchas fronteras en el mundo solamente han sido definidas y delimitadas, pero no demarcadas, como lo señala el mismo autor.

Todo este proceso de fijación y establecimiento de la frontera implica la creación de instituciones, es decir, un conjunto de reglas y normas inherentes al tránsito de la frontera. En efecto, la frontera desempeña tres principales funciones: una función legal (aplicación del derecho positivo de un Estado), una función fiscal (aranceles, retenciones), y una función de control migratorio, así como de bienes y capitales ${ }^{43}$. Este mismo marco jurídico-institucional y normativo se complejifica progresivamente a medida de que los diferentes flujos de personas, así como los flujos de bienes y servicios, se diversifican e intensifican. Las funciones de la frontera integran progresivamente cada vez más parámetros y reglas, y por lo mismo surgen cada vez más posibilidades de eludirlas.

En otros términos, el hecho de regularizar y canalizar la migración y el comercio transfronterizo, formalizando e institucionalizando el tránsito fronterizo, no equivale

${ }^{2}$ ADLER-LOMNITZ, Larissa, Redes sociales, cultura y poder: ensayos de antropología latinoamericana, cit., p. 136.

43 Vid. RAFFESTIN, Claude, «Éléments pour une théorie de la frontière», cit. 
forzosamente a la disminución de las prácticas económicas informales - sobre todo en un contexto marcado por una polarización social y económica como ocurre en las fronteras de México - sino que ofrece nuevas oportunidades económicas informales (e incluso ilegales); así los actores individuales y organizados tratan de maximizar sus intereses implementando estrategias alternativas y buscando soluciones informales para evitar las reglas. Sin embargo, no hay que olvidar que, como lo recuerda Portes, la insatisfacción por las condiciones económicas y de los controles del Estado, no genera informalidad en todas partes y en la misma medida; «el elemento que falta es la capacidad históricamente determinada, de las diferentes comunidades de organizarse para hacerle frente a los controles estatales y al mismo tiempo aprovechar las oportunidades que se crean» 44 .

${ }^{44}$ PORTES, Alejandro, En torno a la informalidad: ensayos sobre teoría y medición de la economía no regulada, México D.F., Facultad Latinoamericana de Ciencias Sociales, Miguel Ángel Porrúa, 1995, p. 199. 


\section{Conclusión}

Los pasos fronterizos entre el estado de Chiapas en México y el departamento de San Marcos en Guatemala, constituyen microrregiones marcadas por una ruptura política y económica originada por la división político-administrativa, y al mismo tiempo por una continuidad sociocultural o existencia de múltiples redes sociales que atraviesan dicho límite. En este contexto específico de frontera caracterizado también por condiciones de pobreza, de desigualdad y de falta de oportunidad laboral, así como problemas relativos a la aplicación de las normas formales y leyes, surgen determinadas prácticas económicas informales.

Como lo vimos, la informalidad difiere de la ilegalidad y concierne un abanico de productos, prácticas y actividades tanto en los países en vías de desarrollo como en los países industrializados. A pesar de la heterogeneidad de la economía informal, se puede identificar regiones en donde una proporción importante de la población económicamente activa se dedica a actividades económicas informales, como en el sureste mexicano y en Guatemala. En el caso de las áreas de frontera entre ambos países, la frontera se vuelve un recurso para las poblaciones fronterizas, sobre todo cuando existen diferencias marcadas a nivel económico y político.

Se puede observar entonces no sólo actividades económicas informales propias de un lugar de paso, como la venta de comida en las calles, sino también prácticas económicas directamente relacionadas con la división político-administrativa. Identificamos un comercio informal que se fundamenta en el diferencial de tipos de cambio, de precios de ciertos artículos, y de la especialización productiva. Por otra parte, existen grupos de personas que brindan servicios complementarios inherentes al tránsito fronterizo, como los pasadores, cargadores, transportistas, tramitadores y cambistas. El conjunto de estas actividades conforma un sistema paralelo de intercambios y transacciones.

Finalmente, vincular ciertos elementos teóricos sobre la informalidad con perspectivas teóricas de la frontera como objeto de estudio permitió rebasar ciertos límites de la noción de "contrabando" y poner de relieve la dimensión estructural del comercio informal transfronterizo; este está intrínsecamente vinculado a la formalización de la frontera, es decir a la creciente reglamentación del tránsito fronterizo de personas y mercancías. 


\section{Anexo 1: la frontera entre México y Guatemala}

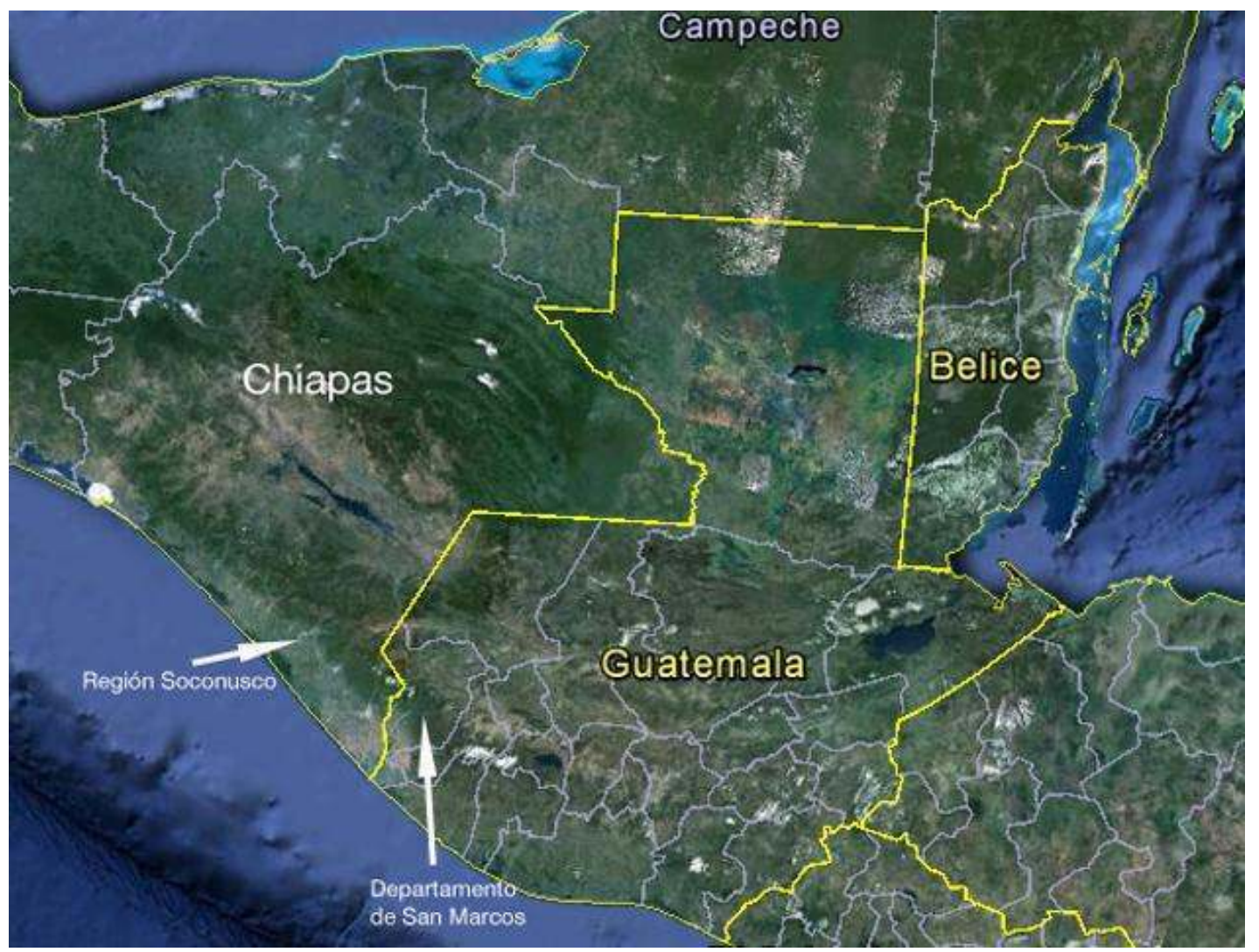

Fuente: Google Earth, 2013 
Anexo 2: un paso fronterizo o "área de frontera" en done colindan las ciudades fronterizas de Ciudad Hidalgo del lado mexicano y de Tecún Umán del lado guatemalteco.

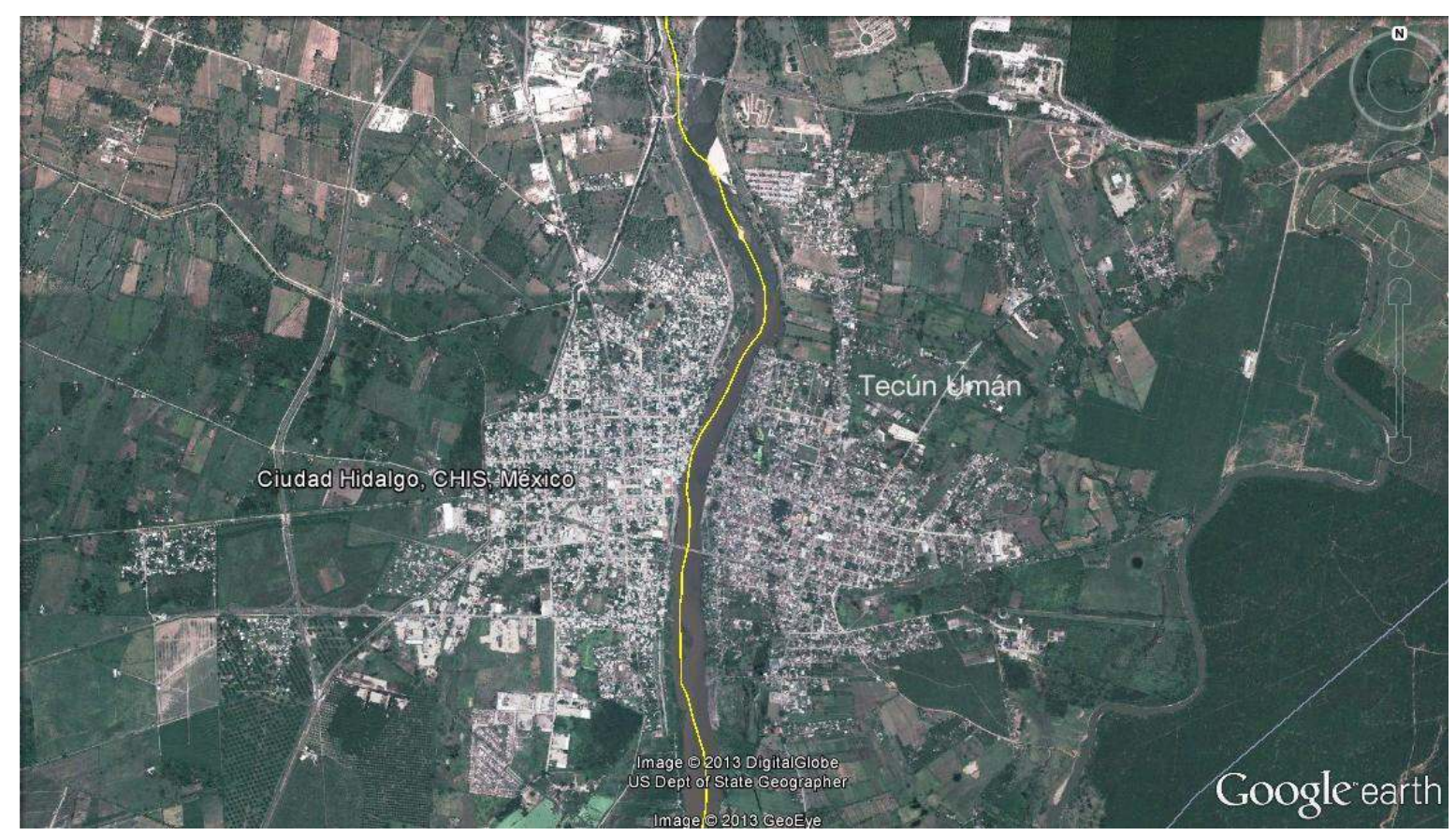

Fuente: Google Earth, 2013. 
Anexo 3: “camareros" y "cargadores" en la orilla del Río Suchiate en Ciudad Hidalgo, México.

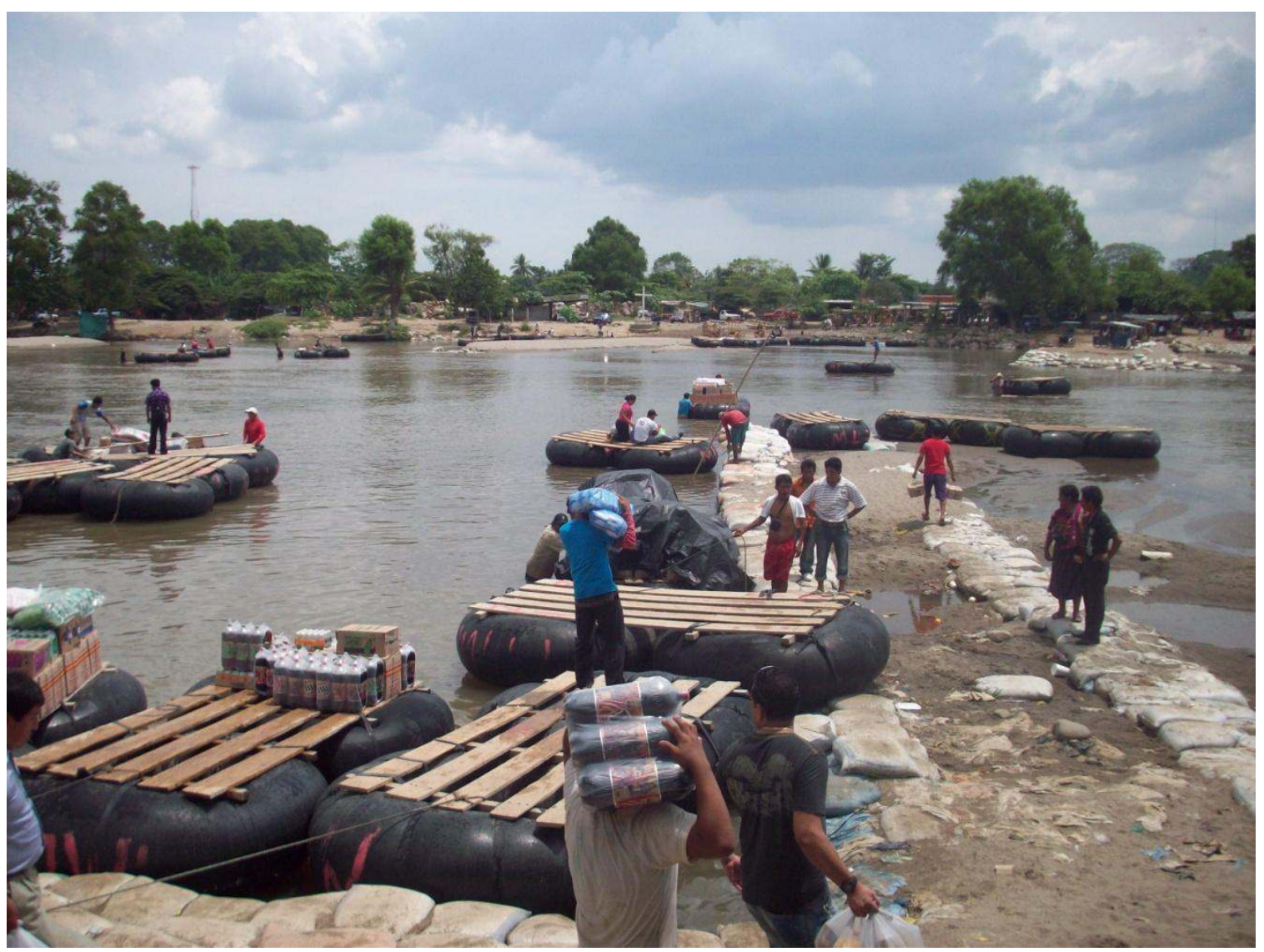

Fuente: imagen propia. 


\section{* El autor}

Jean Clot es doctorante en Estudios Regionales en la Universidad Autónoma de Chiapas, México. Sus líneas de investigación incluyen, entre otros temas, economía informal, frontera y migración.

URL: < http://www.studistorici.com/progett/autori/\#Clot >

\section{Per citare questo articolo:}

CLOT, Jean, «Acercamiento conceptual a las prácticas económicas informales en los pasos fronterizos entre México y Guatemala», Diacronie. Studi di Storia Contemporanea: Contrabbandieri, pirati e frontiere: per una storia delle pratiche informali nell'America Centrale (XVII-XXI secolo), 29/04/2013,

URL:< http://www.studistorici.com/2013/04/29/clot_numero_13/ >

Diacronie Studi di Storia Contemporanea $\beta$ www.diacronie.it

Risorsa digitale indipendente a carattere storiografico. Uscita trimestrale.

redazione.diacronie@hotmail.it

Comitato di redazione: Marco Abram - Jacopo Bassi - Luca Bufarale - Alessandro Cattunar - Elisa Grandi - Deborah Paci - Fausto Pietrancosta - Matteo Tomasoni - Luca Zuccolo

Diritti: gli articoli di Diacronie. Studi di Storia Contemporanea sono pubblicati sotto licenza Creative Commons 2.5. Possono essere riprodotti a patto di non modificarne i contenuti e di non usarli per fini commerciali. La citazione di estratti è comunque sempre autorizzata, nei limiti previsti dalla legge. 